This item was submitted to Loughborough's Research Repository by the author.

Items in Figshare are protected by copyright, with all rights reserved, unless otherwise indicated.

\title{
COVID social distancing and the poor: an analysis of the evidence for
}

\section{England}

PLEASE CITE THE PUBLISHED VERSION

https://doi.org/10.1515/bejm-2020-0250

PUBLISHER

De Gruyter

VERSION

VoR (Version of Record)

PUBLISHER STATEMENT

This is an Open Access Article. It is published by De Gruyter under the Creative Commons Attribution 4.0 International Licence (CC BY 4.0). Full details of this licence are available at: https://creativecommons.org/licenses/by/4.0/

\section{LICENCE}

CC BY 4.0

\section{REPOSITORY RECORD}

Basu, Parantap, Clive Bell, and Huw Edwards. 2021. "COVID Social Distancing and the Poor: An Analysis of the Evidence for England”. Loughborough University. https://hdl.handle.net/2134/13670473.v1. 


\title{
Special Issue
}

\section{Parantap Basu*, Clive Bell and Terence Huw Edwards COVID Social Distancing and the Poor: An Analysis of the Evidence for England}

https://doi.org/10.1515/bejm-2020-0250

Received November 20, 2020; accepted January 31, 2021

\begin{abstract}
Social distancing is a matter of individuals' choices as well as of regulation. We analyse weekly panel data on such behaviour for English Upper Tier Local Authorities (UTLAs) from March to July 2020, paying attention to the influence of poverty, as measured by free school meals provision. Panel regressions suggest that, although more stringent regulation and slightly lagged local cases of infection increase social distancing, both effects are weaker in UTLAs with higher levels of poverty, in part because of poor housing, and also because shortage of money has forced the poor to keep working. Thus motivated, we develop a two-class (rich/poor) model, in which a Nash noncooperative equilibrium arises from individual choices in a regulatory regime with penalties for non-compliance. The model yields results in keeping with the empirical findings, indicating the desirability of generous measures to furlough workers in low-paid jobs as a complement to the stringency of general regulation.
\end{abstract}

Keywords: COVID19, policy stringency, poverty, social distancing

JEL Classification: C23, H00, I00, I12, I14, I18

\footnotetext{
"They fancied themselves free, and no one will ever be free so long as there are pestilences."Albert Camus, The Plague
}

\footnotetext{
*Corresponding author: Parantap Basu, Durham University Business School, Durham, UK, E-mail: parantap.basu@durham.ac.uk

Clive Bell, Universität Heidelberg, Heidelberg, Germany

Terence Huw Edwards, School of Business and Economics, Loughborough University, Loughborough, UK
} 


\section{Introduction}

It is now well known that Covid-19 infections and fatalities can be lowered by social distancing. ${ }^{1}$ Different countries have adopted different measures. In a majority, there is mandatory social distancing (including lockdowns), while in a few, such as Japan and, until recently, Sweden, social distancing has been left to people's choices. A number of studies have already indicated that social distancing is partly endogenous, in the sense that it responds, not just to policy - whether advisory or by diktat - but also voluntarily to the perceived threat (e.g. Chudik, Pesaran, and Rebucci 2020; Toxvaerd 2020).

We address the following questions, paying particular attention to inequality: What are the private incentives for voluntary social distancing when people worry about infection and the loss of income? If people gauge their own private costs and benefits, what dictates their privately optimal choice of social distance? If the government imposes distancing rules, with credible means of enforcement, what effect will they have on social distancing behaviour? In particular, who are likely to respond more to these measures, poor or rich?

Our study is motivated by some evidence on infections and social distancing in the first wave of the virus in England. We have daily COVID test statistics disaggregated by Upper Tier Local Authority (UTLA), which we are able to combine with data on social distancing from Google and regional poverty, as measured by free school meals. Our panel regression results indicate that greater stringency is associated with stronger social distancing; but the poor still distance less than the rich. To the best of our knowledge, there is no other study linking social distancing and inequality in the UK.

We follow this analysis by investigating whether our results are affected by inclusion of data on demographics, manufacturing employment or housing type. We find no significant results for ethnic composition or the proportion of people aged 17-24 in the population, and little effect on the relationship between poverty and social distancing from incorporating the proportion of elderly or the local labour force share of manufacturing. We do, however, find that social distancing varies less in UTLAs where there is more social housing, and that taking account of this reduces somewhat the estimated effects of poverty, indicating that part (but not all) of the relationship between poverty and less social distancing reflects housing conditions.

Motivated by these empirical results, we develop a static microeconomic model of social distancing in a two-class society of rich and poor, who differ in their

1 The authors are grateful to an anonymous referee for very useful comments. The participants in a Hull University webinar workshop are also acknowledged for constructive feedback. Any errors are our own. 
respective costs of social distancing. A Nash equilibrium is analyzed, wherein agents may, in effect, free ride on others' choices when deciding on their own behaviour. Agents choose social distancing so as to minimize the voluntary cost of distancing plus the expected costs of infection. Our main results are, first, that the poor distance less than the rich, and second, that aggregate distancing is decreasing not only in the voluntary costs of distancing faced by the poor, but also in the share of the poor in the population, despite the endogenous choices of the rich. Thirdly, if a mandated minimum social distancing is imposed with a credible penalty, all agents respond by distancing more, but the poor relatively less. These results are consistent with the key empirical findings for England.

The paper is organized as follows. In Section 2, we summarise some of the developing literature on the Covid crisis and the relevant implications. In Section 3, we report our key empirical findings, followed by robustness checks. Section 4 lays out the theoretical model and the main results obtained. Section 5 concludes.

\section{Literature on Social Distancing, Poverty and the Pandemic}

While a number of economists have always had an interest in the economics of communicable disease in poor communities (Malaney, Sielman, and Sachs 2004), the COVID-19 pandemic has spurred a good deal of research, and undoubtedly led to the development of much wider and deeper understanding of the issues (albeit much not yet published in journals). We identify certain important strands.

First, a number of studies have started from the SIR (Susceptible-InfectedResistant) model, central to the epidemiological approach to disease spread, adapting it to take account of behavioural changes in response to the pandemic. We term this 'endogenous social distancing'. Critical theoretical studies on this include Toxvaerd (2020), Eichenbaum, Rebelo, and Trabandt (2020), Farboodi, Jarosch, and Shimer (2020), and Getachew (2020), who use a model of endogenous social distancing to integrate an SIR model into a DSGE framework. ${ }^{2}$ Crucially, empirical evidence has also been emerging of the relevance of treating social distancing as endogenous: see for example Chudik, Pesaran, and Rebucci (2020)'s study of social distancing in China.

2 Alon et al. (2020) integrate an SIR model into an incomplete markets macroeconomic model, focusing upon the effects of differences in age and employment structure, fiscal support and healthcare, indicating that optimal strategy in developing countries, which lack fiscal and healthcare support, and have a smaller proportion of elderly people, should be to shield the vulnerable. 
In contrast to this strand of dynamic modelling, a second strand of papers deals with the link between vulnerability to disease and poverty. This is not novel to COVID: it is well-known in the case of malaria (Malaney, Sielman, and Sachs 2004; Russel 2004). In the early stages of COVID-19, studies suggested that wealthier areas were harder hit (Mukherji and Mukherji 2020), although even at this stage greater inequality implied more disease incidence and deaths. Preliminary U.S. county-level analysis suggested existing rates of poverty, disease and the presence of ethnic minorities were all associated with higher infection rates (Abedi et al. 2020). Against this, enforced social distancing also has very strong differential effects upon the poor compared to the rich (Bonaccorsi et al., 2020; Palomino, Rodriguez, and Sebastian 2020). Glover et al. (2020) also stress the important interaction between virus containment policy and differential impact on poorer social groups. Chan (2020) examines the geography of social distancing in Canada using Facebook data and finds that people living closely together in apartment buildings find it difficult to stay home and maintain a safe social distance. This finding also tallies with Papageorge et al. (2020), who find that people living in these conditions are unlikely to engage in safe social distancing. Brotherhood et al. (2020) study the role of poor slum conditions in two major Brazilian cities, Rio de Janeiro and Sao Paolo, in determining the course of pandemics. They point out that social distancing is very costly for the residents in these slum areas due to their low income status. As a result, social distancing responded less to non-pharmaceutical policy interventions compared to the rest of the country.

Our paper is of interest because it aims at combining these two strands: endogenous social distancing (albeit with less emphasis on the dynamics) and the interaction of the disease with, and implications for, poverty and inequality. Our paper is close in spirit to Brown and Ravallion (2020), who undertake a comprehensive analysis of social distancing behaviour spanning 3000 US counties. Poor families have to depend on short-term and casual labour which makes lock down and mandatory social distancing a costly proposition for them. Moreover, according to Census Bureau of American Houshold survey (AHS) low income households have more more cramped apartments. They also need to use public transportation more often. Although the two papers share a similar premise - that inequality results in lower levels of distancing - they differ in several respects. Our theoretical framework involves an equilibrium, in which individuals make Nash conjectures about others' distancing behaviour. We highlight the role of individuals' free-riding incentives in Nash equilibrium. We also address an important policy question about the efficacy of mandatory minimum distancing rules and how it is diminished in the presence of inequality, while their model does not address this issue. 
Our results provide policy implications about the stringency of social distancing measures, and as such can be seen as complementing studies such as Dergiades, Milas, and Panagiotidis (2020), who use cross-country data to investigate the effectiveness of government policy stringency. In this regard, we are suggesting that, since poor and rich may respond differently, policy needs to take this into account.

\section{COVID in England: Stylized Facts and Empirical Analysis}

A number of studies cited in Section 2 have indicated that social distancing is partly endogenous, in the sense that it responds to virus threats. We investigate whether the poor differ in terms of their responses both to threats and to central policy stringency. It is known that death rates are higher among poorer people, but this may reflect the greater prevalence of other medical conditions among the poor. Even evidence of greater disease spread among poor communities may reflect the effects of crowding rather than a failure to change behaviour. ${ }^{3}$ When it comes to measuring behavioural changes, extensive daily data are available from Google, differentiated regionally for some countries.

Our focus is on England, partly because it represented a single regulatory regime at any one time, ${ }^{4}$ but that regime in fact changed dramatically in midMarch, as policymakers reassessed the situation. For England (rather than the whole UK) we have daily COVID test statistics disaggregated by Upper Tier Local Authority (UTLA), which we are able to combine, in particular, with data from Google. One reason for stopping at the beginning of August is that local lockdowns became more prevalent after this date, which would require the use of alternative policy stringency data. ${ }^{5}$

3 The US study by Papageorge et al. (2020) is a useful contribution, however.

4 There was a single national policy for England, until the government imposed local lockdowns in July, starting in Leicester.

5 This would potentially be a good extension of the study, but raises serious questions of policy endogeneity. Testing had also become much more extensive by that time, and continued to expand throughout the second half of 2020, making infection rate data inconsistent with the first wave. Consequently, we do not extend the study here. 


\subsection{Data Sources}

Daily and cumulative data on diagnosed cases are presented by English UTLA on the UK government's coronavirus dashboard, ${ }^{6}$ along with daily total and cumulative deaths, although only for England as a whole. We concentrate on data for the period 5th March-25th July, and in fact, since we aggregate local cases weekly (to reduce zeroes), we effectively start on 12th March.

Figure 1 shows a clear pattern in the initial wave of the infection: taking off in the middle of March and peaking in early April (the lockdown from 23rd March halting and reversing the growth of the disease with roughly a three-week delay), and then declining gradually. Importantly, it also shows considerable heterogeneity across the 83 local authorities at any one time. We drop Leicester from our sample as an outlier, also partly because it had a local lockdown in July. Figure 1 also shows an outlier in the earlier stages of the disease, namely Devon, which is also dropped. ${ }^{7}$ Our period can be viewed as covering the first wave of the pandemic, and, with the exception of Leicester (which we drop from the sample), predates the second wave, where national policy stringency has been partially

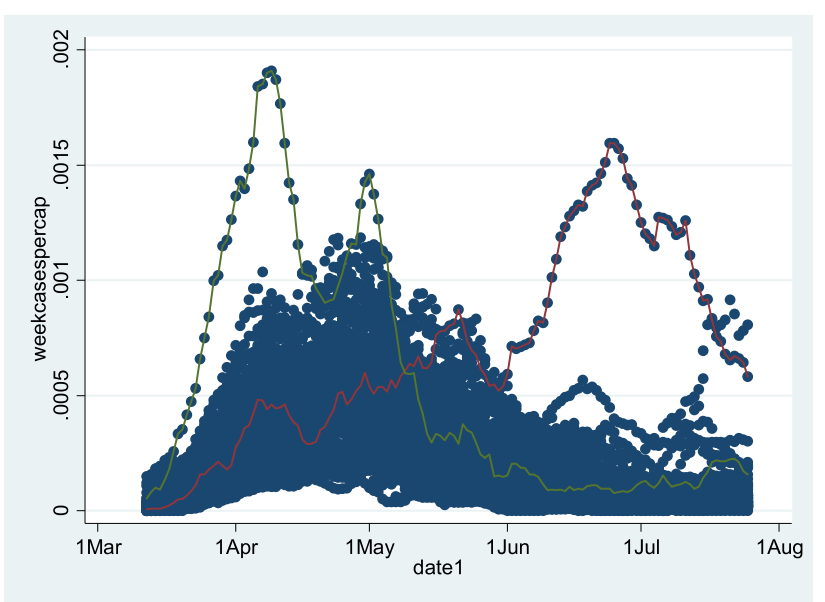

Figure 1: England:New diagnosed cases per week by local authority. Leicester in red. Devon in green.

6 On https://coronavirus.data.gov.uk/category=utlasmap=rate.

7 Incidentally, despite its salubrious image, Devon has the highest rate of poverty in England, measured by free school meals. Leicester is 13th out of 83 UTLAs. 
supplanted by local lockdowns, and also where the infection rates are harder to compare with the first wave, as testing rates of those with symptoms had increased greatly.

The Blavatnik School at Oxford ${ }^{8}$ has compiled daily indices of policy stringency for many countries: we show the UK in Figure 2, alongside a series of French stringency data from the same source, for comparison.

Google publishes daily data on several measures of social distancing, based upon logins with mobile phones. Data are available online since April 2020 as the Google Community Mobility Reports. ${ }^{9}$ These data are available internationally, and have been used by Brown and Ravallion (2020) ${ }^{10}$ and Basu, Bell, and Edwards (2020). For the UK. Google's Community Mobility Reports publish six data series, based upon logins at different locations. All series are available by Upper Tier Local Authority (UTLA) and day, which means over 80 separate observations for each day in a panel. Sadly, data are aggregate for metropolitan counties.

The series are for RESIDENTIAL logins, as well as logins at WORK (workplaces), TRANSIT hubs, places of (non-necessity) retail and recreation (RETREC),

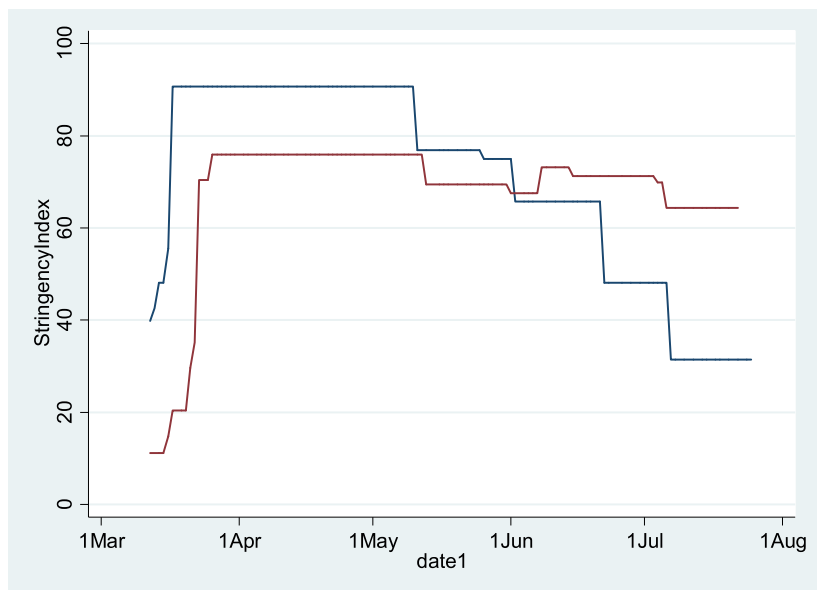

Figure 2: Oxford index of policy stringency for the UK in red. France is in blue for comparison.

8 https://www.bsg.ox.ac.uk/research/research-projects/coronavirus-government-responsetracker.

9 https://www.google.com/covid19/mobility/.

10 Although Brown and Ravallion (2020) primarily use Unacast's data on distance travelled by mobile phone users, which is available for the USA at county level. 
as well as essential shops (groceries and pharmacies, GROCPHARM) and PARKS. Considering these in turn as possible measures of social distancing, the increase in the first, RESIDENTIAL, indicates that people are staying at home more, which was one of the main government recommendations when the UK instituted its lockdown in March. Higher RESIDENTIAL logins are our main preferred measure of social distancing, since they will increase as people switch to travelling less and working from home (hence negatively correlated with TRANSIT and WORK logins), and shopping and socialising less (fewer logins at RETREC). The last two categories are less obvious measures of social distancing, since people will still need to visit essential shops (GROCPHARM), and the impact of a lockdown on exercising in open spaces (PARKS) is likely to be ambiguous. Hence, we focus particularly on RESIDENTIAL logins as our main social distancing measure, with some examination also of WORK, TRANSIT and RETREC.

Although there are clear trends in social distancing over time across England, there are also significant differences by local authority, which cannot be attributed to differences in national policy stringency. Hence, as with the UTLA COVID data, we have cross-sectional variation, as well as variation over time.

Summary statistics of the main data used in our study are shown in Table 1. Note that, when we carry out panel regressions, most data are normalised (divided by their sample means), to make coefficients on different variables more comparable.

\subsection{Panel Regression Analysis of Social Distancing}

In this section, we estimate behavioural equations for social distancing, focusing on its response to policy stringency and to disease-rates, and the role of local poverty variations in accounting for differences in the behavioural responses.

We define $X_{i, j, t}$ as an index of social distancing variable $i$ across UTLA, $j$, and time, $t$. Overall, we examine four social distancing variables, which we index $i=$ [RESIDENTIAL, WORK, TRANSIT and RETREC (Retail/Recreational) logins], although we focus primarily upon the first of these, RESIDENTIAL logins. We note that for RESIDENTIAL logins, an increase (+) indicates increasing social distancing, while for the other three variables a decrease (-) indicates greater social distancing.

We wish to estimate these four social distancing variables as functions of national policy stringency, $S_{t}$, local weekly cases of covid, $W_{j, t}$, and indices, $P_{k, j}$, of local time-invariant features, $k$, such as poverty rates (which we proxy by the proportion of children receiving free school meals, ${ }^{11}$ which we denote 'fsm') and population density. In addition, we incorporate day of the week and bank holiday

11 A means tested benefit in the U.K. 
Table 1: Descriptive statistics of key variables.

\begin{tabular}{|c|c|c|c|c|c|}
\hline Variable & Obs & Mean & Std. Dev. & Min & Max \\
\hline \multicolumn{6}{|l|}{ All 83 UTLAs } \\
\hline Weekcasespercap & 11,288 & 0.0002412 & 0.0002398 & 0 & 0.0019095 \\
\hline Popdensity & 11,288 & 1853.575 & 2718.248 & 64 & 16237 \\
\hline Fsm & 11,288 & 14.60226 & 6.746104 & 4.288068 & 33.60141 \\
\hline Stringency & 11,039 & 67.32564 & 15.2776 & 11.11 & 75.93 \\
\hline TRANSIT & 11,288 & -47.44835 & 20.85276 & -92 & 65 \\
\hline WORK & 11,288 & -46.552 & 19.02245 & -90 & 5 \\
\hline RESIDENTIAL & 11,288 & 17.93568 & 7.570169 & 0 & 38 \\
\hline RETREC & 11,288 & -56.30351 & 21.08143 & -95 & 27 \\
\hline \multicolumn{6}{|l|}{ LOW POVERTY UTLAS } \\
\hline Weekcasespercap & 1,360 & 0.0001745 & 0.0001659 & 0 & 0.0007041 \\
\hline Popdensity & 1,360 & 473.9 & 243.7461 & 169 & 956 \\
\hline Fsm & 1,360 & 6.310654 & 0.8651854 & 4.288068 & 7.359261 \\
\hline Stringency & 1,330 & 67.32564 & 15.28265 & 11.11 & 75.93 \\
\hline TRANSIT & 1,360 & -46.225 & 19.46876 & -85 & 31 \\
\hline WORK & 1,360 & -48.02574 & 20.02923 & -90 & 5 \\
\hline RESIDENTIAL & 1,360 & 19.40882 & 7.923043 & 0 & 35 \\
\hline RETREC & 1,360 & -56.97206 & 21.23319 & -91 & 10 \\
\hline \multicolumn{6}{|c|}{ HIGH POVERTY UTLAS } \\
\hline Weekcasespercap & 1,360 & 0.0003229 & 0.0002875 & 0 & 0.0011856 \\
\hline Popdensity & 1,360 & 2624.864 & 2731.434 & 74 & 9696 \\
\hline Fsm & 1,360 & 27.49061 & 2.36961 & 24.96368 & 33.60141 \\
\hline Stringency & 1,330 & 67.32564 & 15.28265 & 11.11 & 75.93 \\
\hline TRANSIT & 1,360 & -46.23824 & 20.73862 & -85 & 55 \\
\hline WORK & 1,360 & -44.40882 & 18.24921 & -85 & 4 \\
\hline RESIDENTIAL & 1,360 & 16.65515 & 6.756528 & 0 & 33 \\
\hline RETREC & 1,360 & -56.25588 & 21.09952 & -94 & 15 \\
\hline
\end{tabular}

dummies, which we denote as $D_{d, t}$, where $d$ is the type of dummy (e.g. bank holiday). Hence we formulate

$$
X_{i, j, t}=X\left\{S_{t}, W_{j, t}, P_{k, j}, D_{d, t}\right\} .
$$

Since the social distancing variables $X_{i, j, t}$ can take positive or negative values, it is not appropriate to use a logarithmic formulation: for simplicity we apply a linear formulation, such as the following, which can be estimated either by ordinary least squares or as a random effects (RE) model:

$$
\begin{aligned}
X_{i, j, t}= & \alpha_{i}+\beta_{i, 1} S_{t}+\beta_{i, 2} W_{j, t}+\sum_{k} \gamma_{i, k} P_{k, j}+\sum_{k}\left\{\delta_{i, 1, k} P_{k, j} S_{t}+\delta_{i, 2, k} P_{k, j} W_{j, t}\right\} \\
& +\sum_{d} \theta_{i, d} D_{d, t}+u_{i, j, t} .
\end{aligned}
$$


The day type variables $D_{d, t}$ are essentially included as controls. We also interact these with the other variables $\left(S_{t}, W_{j, t}\right.$ etc.), but again just as controls. The model specification incorporates interaction terms between all of the time invariant features $P_{k, j}$ and national stringency $S_{t}$, and between the various $P_{k, j}$ and all of the local weekly infections $W_{j, t}$. These interactions are central to our study, as they indicate whether fsm and/or population density enhance the effects of $S_{t}$ and/or $W_{j, t}$.

It is also possible to estimate the corresponding fixed effects (FE) model. In the first instance, this incorporates UTLA-specific errors, $\epsilon_{i, j}$, which imply that timeinvariant UTLA-specific data, such as population density and fsm uptake, have to be dropped due to multicollinearity. In addition, one can incorporate time-specific fixed effects or dummies, $\eta_{i, t}$. If we include these, then we can no longer take advantage of the variation in time in national policy stringency (since changes in this were common, over time, to all UTLAs, until the local lockdown in Leicester in July), or indeed in common (national) time trends in infection rates, although local variations in infection rates and the interaction terms with UTLA-level socioeconomic variables remain. Hence the equivalent FE model to Eq. (2) is:

$$
X_{i, j, t}=\alpha_{i}+\beta_{i, 2} W_{j, t}+\sum_{k}\left\{\delta_{i, 1, k} P_{k, j} S_{t}+\delta_{i, 2, k} P_{k, j} W_{j, t}\right\}+\epsilon_{i, j}+\eta_{i, t}+u_{i, j, t} .
$$

In general, while statistical tests (Hausman or Sargan-Hansen) often favour the use of fixed effects, dependent upon the data, such a specification may end up proxying most of the variation in variables such as disease rates, in which case an OLS or RE model may be more informative.

Our tentative hypothesis is not only that greater stringency should raise social distancing, but also that the effect of this policy would depend on various local fixed effects. Among these fixed effects, we focus on poverty. Our hypothesis is motivated by the fact that UTLAs with high proportions of children receiving free school meals ('fsm') show less social distancing. This is shown in Figure 3, focusing on the RESIDENTIAL variable, and comparing the highest and lowest UTLAs, ranked in terms of fsm. This motivates us to add interaction terms with fsm. We normalise all explanatory variables, by dividing by their mean values. This means that estimated coefficients are marginal effects at the mean values of the explanatory variables.

Table 2 summarises the results of this analysis. The first three columns refer to the social distancing variable RESIDENTIAL: as discussed above, an increase in this variable can be considered as an increase in social distancing. Column (1) is a panel RE regression across all 81 UTLAs (excluding Devon and Leicester), without any instrumentation or time or UTLA dummies. In column (2) we include fixed effects for UTLAs only, while in column (3), time dummies (fixed effects) are also 


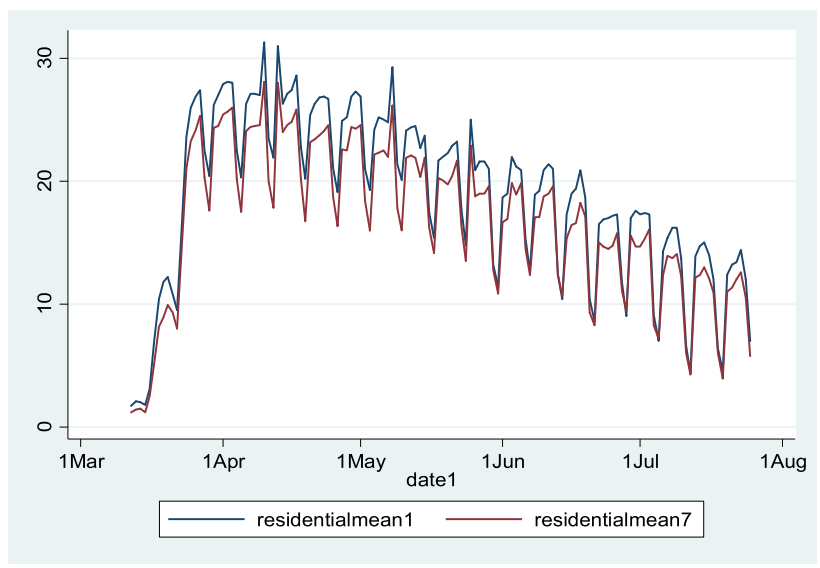

Figure 3: a) Mean RESIDENTIAL logins by UTLAs ranked 1-10 (Group 1) and 70-81 (Group 7) in terms of lowest free school meals uptake. Group 1 has the least poverty, and 7 has the most.

included. It is worth noting that estimated coefficients are almost identical across the first two models. Tentatively, we therefore discuss the equation in panel (1) as our preferred choice.

The estimated coefficient on stringency for RESIDENTIAL logins is +17.51 , indicating that increased policy stringency (lockdown) increases social distancing. This variable is modestly but (statistically) significantly increased by population density (marginal effect of the interaction +0.508$)$, and reduced $(-1.715$ mean marginal effect) by the free school meals variable (the poor respond less to policy, on this measure).

There is also evidence of endogenous social distancing: local weekly cases per capita ${ }^{12}$ have a positive effect ( +4.304 at the mean) on RESIDENTIAL logins. This is only about $1 / 4$ of the effect of stringency (although at the peak weekly cases went well above their mean level, so implying a stronger effect). Greater population density significantly increases this endogenous social distancing (by +0.330$)$, but the endogenous social distancing effect is reduced (by -1.425 or about $1 / 3$ at the mean) by poverty, as measured by free school meals. ${ }^{13}$

For comparison, the FE model with time dummies in column (3) shows much smaller and less significant coefficients (except on stringency), although the interaction between weekly cases and free school meals remains negative and

12 Cases diagnosed in the previous seven days.

13 Weekly cases respond to social distancing measures only with 2-3 week lags, so we judge endogeneity not to be a major issue with this variable. 


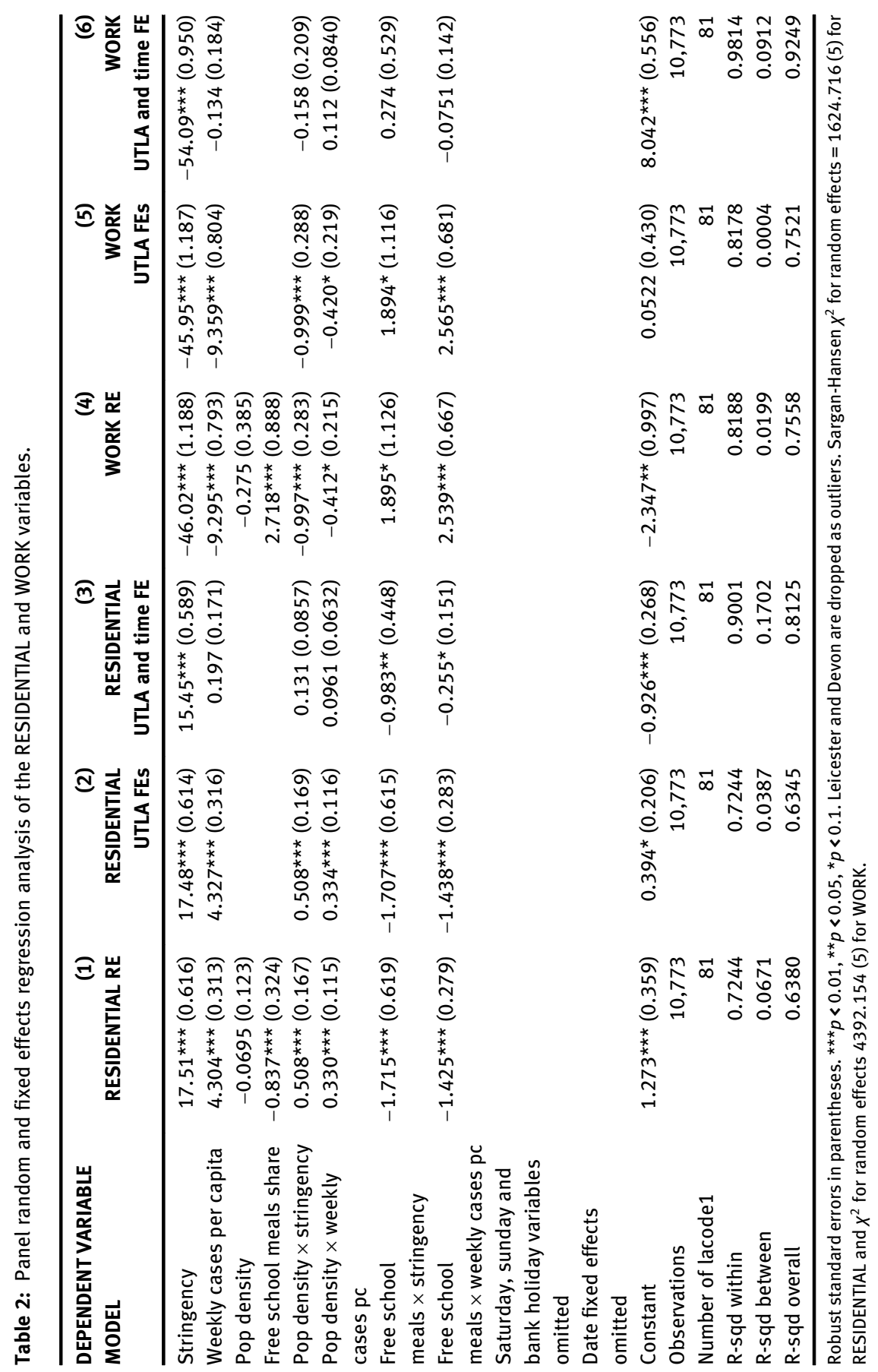


significant at the $10 \%$ level. In general, the FE model with time dummies/fixed effects provides a stronger statistical fit (as indicated by the Sargan-Hansen test), ${ }^{14}$ but is less behaviourally informative. This indicates that the most useful information on social distancing comes from the longitutinal (time-varying) dimension of the model, which is lost when time fixed effects are included.

\subsection{Estimated Models for Other Social Distancing Variables: WORK, TRANSIT and Retail/Recreational}

As a first test, we investigate three of the other Google measures, to see whether similar patterns of behaviour emerge. Starting with WORK logins, which are shown in columns (4)-(6) of Table 2, many of the same comments apply, except that the signs on estimated coefficients are reversed (since lower work logins imply more social distancing). Stringency is clearly strongly significant: -46.02 in column (4), with marginal effects also of -0.997 from the interaction with population density, but +1.895 from the interaction with free school meals. Poverty weakens the reaction to policy stringency. Regarding endogenous social distancing, there is a strong negative effect (-9.295) from weekly cases, but reduced significantly $(+2.539)$ by the interaction with free school meals. Hence, poverty reduces endogenous social distancing. The model with UTLA fixed effects in column (5) is virtually identical to the random effects model - while once time fixed effects are included (column (6)), significance is lost on almost all variables except policy stringency.

Columns (1)-(3) of Table 3 cover TRANSIT (public transport logins). As in Table 2, the first two formulations scarcely differ. Again, we focus on column (1), the random effects regression. Policy stringency has a strong negative (i.e. social distance increasing) effect on this measure, with a basic coefficient of -35.16 , plus a significant marginal effect of -1.485 from the interaction with population density (and an insignificant interaction with free school meals). Weekly cases show a strong negative effect $(-11.55)$, which is increased somewhat by the interaction with population density (marginal effect -0.713), but strongly and significantly reduced by the interaction with free school meals (+4.241). Hence, again, endogenous social distancing exists, but is weakened where there is high inequality. The introduction of time fixed effects in column (3) renders all coefficients except stringency insignificant.

For retail and recreational (RETREC) logins, again we have a very similar message. Focusing on the random effects model in column (4), there is a strongly

14 We use Sargan-Hansen rather than the Hausman test due to the use of robust standard errors. 


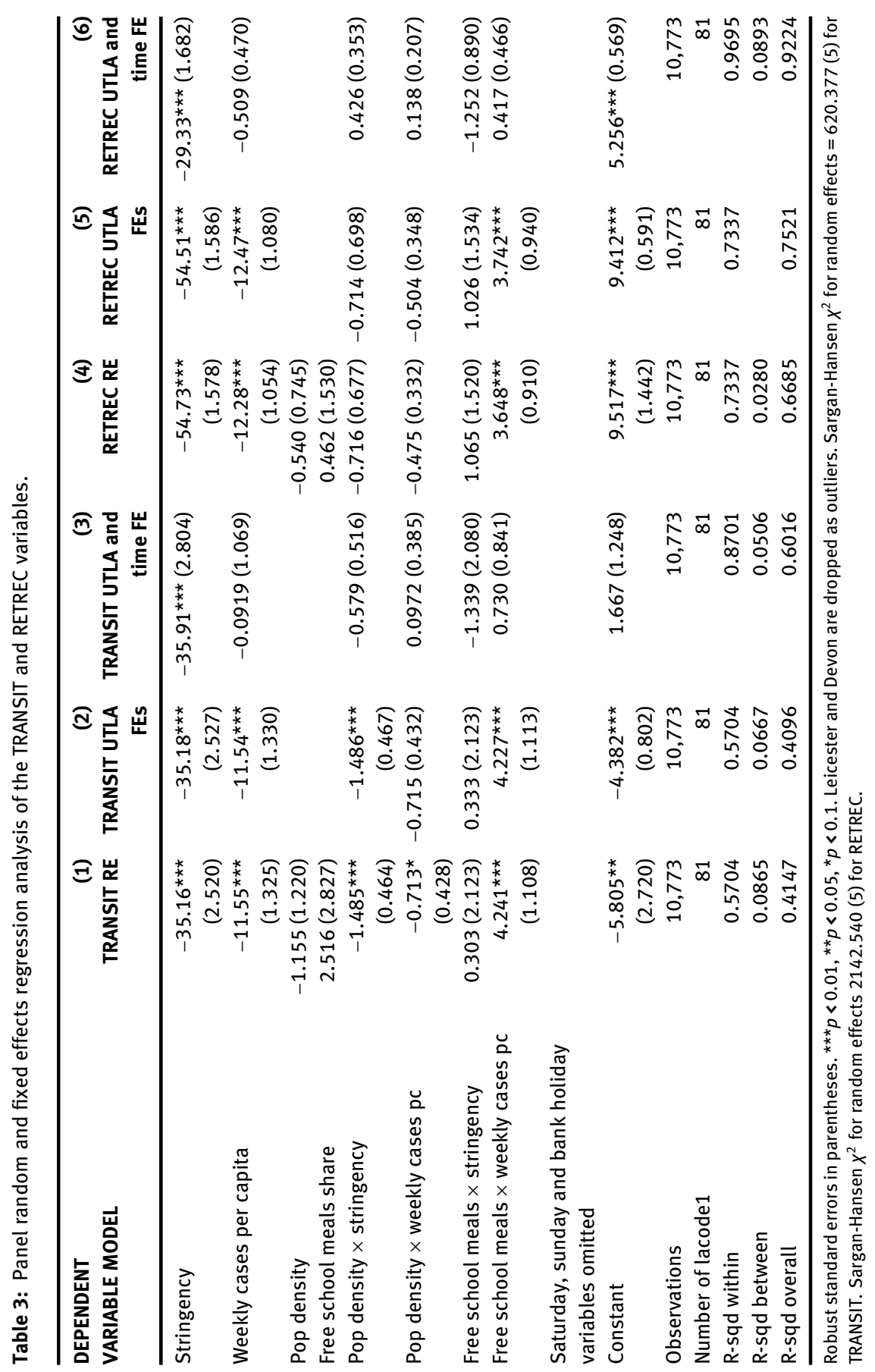


significant negative (i.e. social distance increasing) coefficient on stringency, and likewise (though again between 1/3 and 1/4 of the marginal effect) for weekly cases, indicating endogenous social distancing. The significant positive interaction of weekly cases and free school meals indicates that the poor have less endogenous social distancing, while other coefficients are insignificant. UTLA fixed effects in column (5) make virtually no difference, while time fixed effects in column (6) again sadly wipe out most significant effects.

\subsection{Potential Explanations of the Links Between Poverty and Lack of Social Distancing}

In section 2 we have already discussed a number of potential factors identified in the literature affecting the spread of Covid 19, many of which may be correlated with, or caused by, poverty. We will discuss a number of these in detail here,

First of all, demographics are worthy of consideration. We have already noted that ethnic minorities tend to have higher infection rates (Abedi et al. 2020). While some of this may reflect an inherited predisposition to contracting the disease, or developing it badly enough to be recorded, the US study by Brown and Ravallion (2020) did find ethnic minorities were less likely to socially distance. Anecdotally, this would be backed by the observation that the Leicester spike in the UK was driven by poorer people of Asian descent, partly because they continued to work during the pandemic in crowded garment factories. This also indicates that the share of manufacturing may play a part as well, since factory workers cannot shift to working from home. ${ }^{15}$

Other demographics include the age structure of the population. For example, since older people are likely to go out of home less anyway, their social distancing may change less in response to the pandemic. By contrast, many newspaper commentators have noted the unwillingness of younger adults to socially distance or stay at home. If infected, the young are also much more likely to be asymptomatic, and hence correspondingly less likely to contribute to reported cases when testing is limited.

In addition, poor quality housing has been noted as being associated with disease spread (Brotherhood et al. 2020; Chan 2020; Papageorge et al. 2020). Of course, some of this may reflect individuals' difficulty in maintaining distance within a crowded house (which would not show up in our social distancing data),

15 Note also that food processing plants are particularly likely to spread the virus, due to low workplace temperature. However, this latter observation does not affect our social distancing measures. 
but it may also be that people in less salubrious housing may be reluctant to spend time at home during the pandemic. Given the housing stock, housing costs are mutually and simultaneously determined with income-earning opportunities, locational choices and commuting costs, so that interpreting the estimated effects of housing costs may not be easy. However, by incorporating these in conjunction with a poverty measure, at least some omitted variable bias is removed (at the potential cost of some collinearity).

We investigate these potential factors using data on the demographic composition of the population by UTLA (non-white population share, share of 1724 year olds, share of over 60 year olds) and the share of manufacturing in the occupation of the local workforce. ${ }^{16}$ In addition, we utilise data on the share of the local housing stock which is owned by housing associations or councils (while acknowledging that this will not correlate perfectly with poorer-quality housing). ${ }^{17}$

For any of these factors to explain our observed relationship between poverty and reduced social distancing, there would have to be a strong correlation between the variable concerned and our main poverty measure (free school meals). Column (6) of Table 4 investigates this. In fact, the strongest (positive) correlation is between housing type and free school meals. Poorer areas also tend to have higher shares of non-white people and 17-24 year olds, but in both cases the correlation coefficient is only moderate $(+0.2$ or so). The share of over 60 s is negatively correlated with our poverty measure, while manufacturing is virtually uncorrelated with it.

Table 4: Descriptive statistics of additional demographic and housing variables.

\begin{tabular}{lrrrrrr}
\hline Variable & $\begin{array}{r}(1) \\
\text { Obs }\end{array}$ & $\begin{array}{r}(2) \\
\text { Mean }\end{array}$ & $\begin{array}{r}\text { (3) } \\
\text { Std. Dev. }\end{array}$ & $\begin{array}{r}\text { (4) } \\
\text { Min }\end{array}$ & $\begin{array}{r}\text { (5) } \\
\text { Max }\end{array}$ & $\begin{array}{r}\text { (6) } \\
\text { Correlation } \\
\text { with fsm }\end{array}$ \\
\hline Non-white popshare & 83 & 0.1162768 & 0.1278951 & 0.015 & 0.548 & 0.2019 \\
17-24 years old share & 83 & 0.1011381 & 0.0292283 & 0.0718865 & 0.2252875 & 0.2246 \\
Over 60s share & 83 & 0.2572155 & 0.0536347 & 0.1189925 & 0.3660728 & -0.3226 \\
Manufacturing share & 83 & 9.231004 & 4.478967 & 1 & 23 & 0.0051 \\
Social housing share & 83 & 0.1613317 & 0.0488842 & 0.0699744 & 0.3579016 & 0.5138 \\
\hline
\end{tabular}

16 Source: https://www.ons.gov.uk/peoplepopulationandcommunity/populationandmigration/ populationestimates/articles/populationprofilesforlocalauthoritiesinengland/2020-12-14. 17 Source: https://www.gov.uk/government/collections/local-authority-housing-data. 
Tables 5 and 6 investigate the relationship of these demographic and housing variables to our first social distancing measure (RESIDENTIAL logins), by adding them to the equations estimated in Table 2. We discuss these tables together, so we label the columns in Table 5 (1)-(6), while (7)-(9) are in Table 6. Columns (1), (4) and (7) correspond to columns (1)-(3) in Table 2 (random effects, UTLA fixed effects and UTLA fixed effects with time dummies). Columns (2), (5) and (8) add in demographic variables, as well as the share of manufacturing in employment, while (3), (6) and (9) also include our social housing variable (share of council plus housing association houses in total).

Starting with the demographic and labour variables in columns (2), (5) and (8), the non-white share and the share of 17-24s and their interactions with stringency and weekly cases are all insignificant. The share of the over $60 \mathrm{~s}$ is mostly insignificant, but in columns (8) and (9) there is a significant negative interaction with stringency, implying that the elderly change their behaviour less in response to the pandemic and lockdown, presumably because they were at home more to start with. The share of manufacturing has a negative effect on domestic logins in the random effects model, and there is evidence in the model with time dummies in columns (8) and (9) that manufacturing workers increased time spent at home less in response to policy stringency, presumably because factories kept running. Nevertheless, comparing columns (1) with (2), (4) with (5) and (7) with (8), there is almost no change in the estimated coefficients for the effects of poverty (free school meals) when these demographic variables are included. Specifically, the interaction term of free school meals and stringency remains highly significant around -1.8 in both the random effects model and the area fixed effects model, and falls slightly from -0.983 to -0.725 in the model with time dummies. The interaction with weekly cases falls slightly, from around -1.4 to about -1.25 with random or area fixed effects, but is insignificant in the case with time dummies. It follows that the effect of poverty on social distancing does not reflect population composition. While a concentration of manufacturing does reduce social distancing, this is virtually orthogonal to our poverty measure (correlation coefficient in Table 4), so this is unrelated to the association of poverty with less social distancing.

Turning to housing, as shown in columns (3), (6) and (9), the only significant variable (in each case) is the interaction with weekly cases per capita. This indicates that, in areas with more social housing, there is less response of RESIDENTIAL logins to changes in local disease prevalence over time. In these three columns, the interaction term for free school meals with weekly cases is correspondingly reduced once housing is included: for example, from -1.252 in the random effects model in Column (2) to -1.032 in Column (3) with social housing introduced, while the interaction of social housing with weekly cases has a 


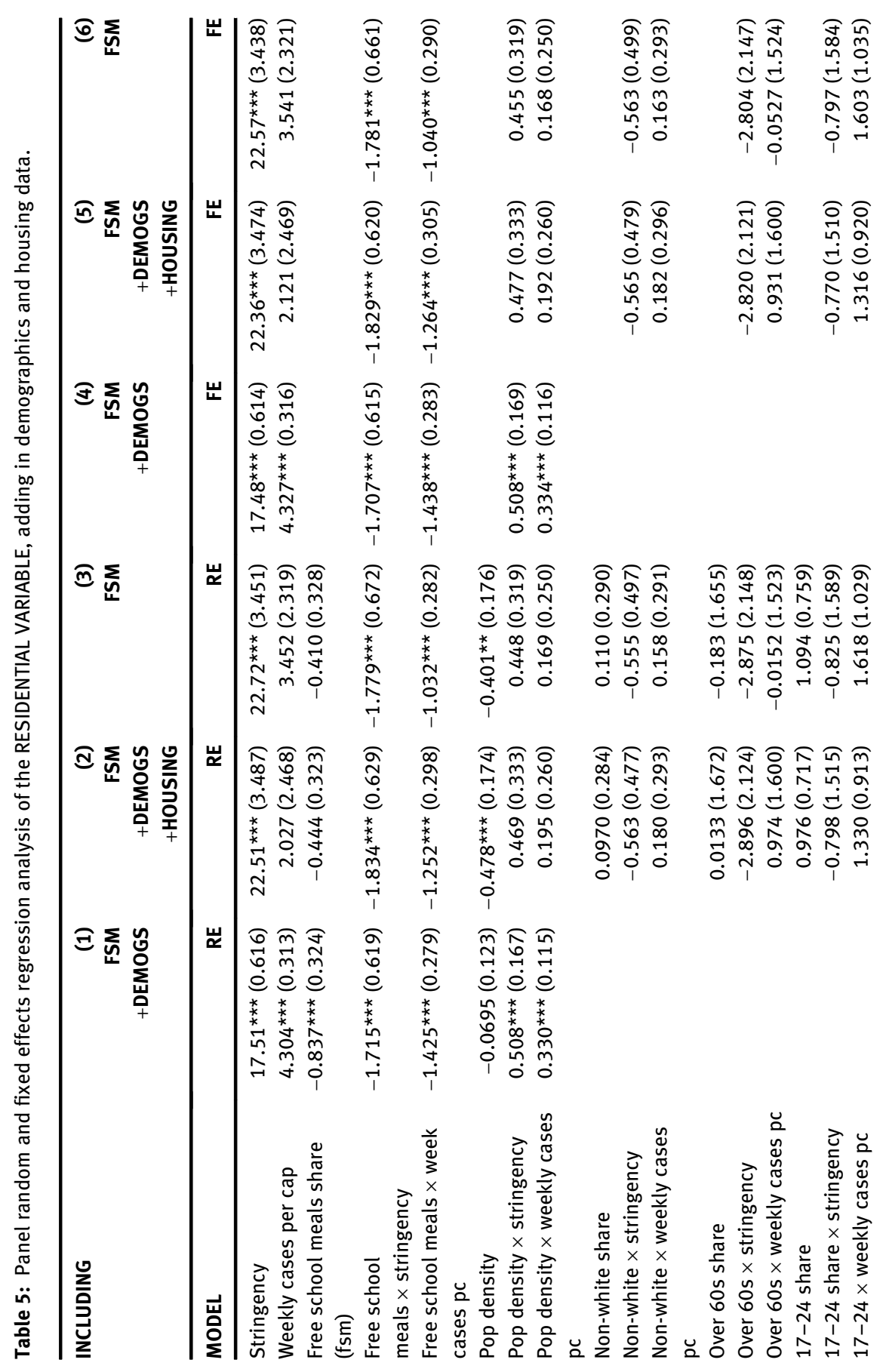




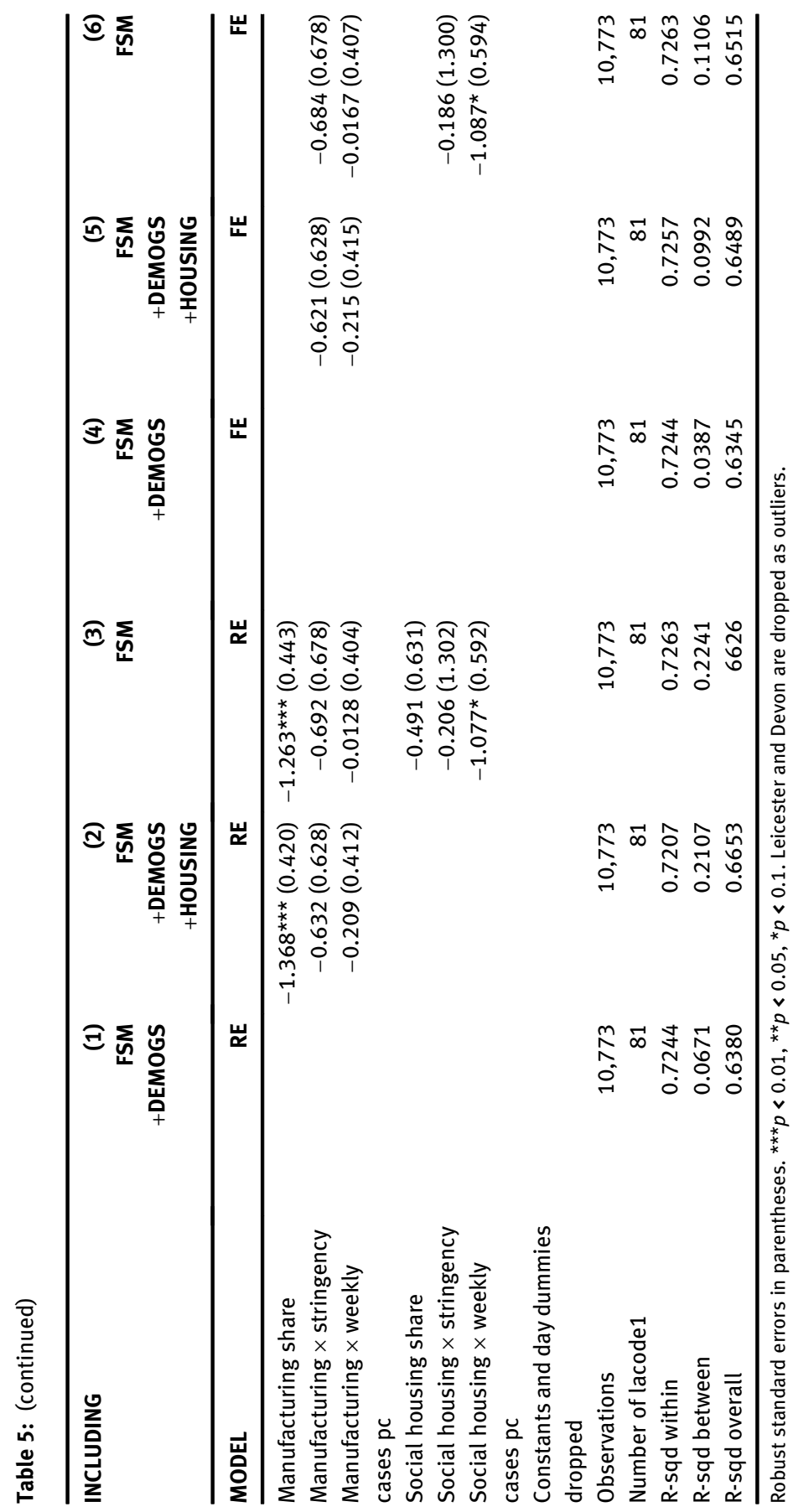


Table 6: Panel fixed effects regression analysis of the RESIDENTIAL VARIABLE, adding in demographics and housing data.

\begin{tabular}{|c|c|c|c|}
\hline INCLUDING & $\begin{array}{r}(7) \\
\text { FSM }\end{array}$ & $\begin{array}{r}(\mathbf{8}) \\
\text { FSM } \\
+ \text { DEMOGS }\end{array}$ & $\begin{array}{r}(9) \\
\text { FSM } \\
\text { +DEMOGS } \\
\text { +HOUSING }\end{array}$ \\
\hline MODEL & $\begin{array}{r}\text { FE with time } \\
\text { dummies }\end{array}$ & $\begin{array}{r}\text { FE with time } \\
\text { dummies }\end{array}$ & $\begin{array}{r}\text { FE with time } \\
\text { dummies }\end{array}$ \\
\hline Stringency & $15.45^{\star \star \star}(0.589)$ & $21.57^{\star \star \star}(2.523)$ & $21.93^{\star \star \star}(2.627)$ \\
\hline Weekly cases per cap & $0.197(0.171)$ & $0.635(0.930)$ & $1.647^{\star}(0.954)$ \\
\hline Free school meals $\times$ stringency & $-0.983^{\star \star}(0.448)$ & $-0.725^{\star}(0.417)$ & $-0.655(0.419)$ \\
\hline $\begin{array}{l}\text { Free school meals } \times \text { weekly cases } \\
\text { pc }\end{array}$ & $-0.255^{\star}(0.151)$ & $-0.208(0.143)$ & $-0.0542(0.137)$ \\
\hline Pop density $\times$ stringency & $0.131(0.0857)$ & $-0.274^{\star}(0.151)$ & $-0.276^{\star}(0.163)$ \\
\hline Pop density $\times$ weekly cases $p c$ & $0.0961(0.0632)$ & $-0.0222(0.103)$ & $-0.0410(0.0842)$ \\
\hline Non-white $\times$ stringency & & $-0.287(0.230)$ & $-0.277(0.241)$ \\
\hline Non-white $\times$ weekly cases $p c$ & & $0.0219(0.115)$ & $0.00692(0.112)$ \\
\hline Over $60 \mathrm{~s} \times$ stringency & & $-3.517^{\star \star}(1.491)$ & $-3.618^{\star \star}(1.528)$ \\
\hline Over $60 \mathrm{~s} \times$ weekly cases $\mathrm{pc}$ & & $-0.462(0.553)$ & $-1.157^{\star \star}(0.567)$ \\
\hline $17-24 \mathrm{~s} \times$ stringency & & $-0.860(0.844)$ & $-0.833(0.866)$ \\
\hline 17-24s × weekly cases pc & & $0.107(0.349)$ & $0.311(0.330)$ \\
\hline Manufacturing $\times$ stringency & & $-1.351 * \star \star(0.342)$ & $-1.362^{\star \star \star}(0.347)$ \\
\hline Manufacturing $\times$ weekly cases $\mathrm{pc}$ & & $-0.0548(0.155)$ & $0.0839(0.149)$ \\
\hline Social housing $\times$ stringency & & & $-0.371(0.915)$ \\
\hline Social housing $\times$ weekly cases $\mathrm{pc}$ & & & $-0.758^{\star \star \star}(0.247)$ \\
\hline Observations & 10,773 & 10,773 & 10,773 \\
\hline Number of lacode 1 & 81 & 81 & 81 \\
\hline R-sqd within & 0.9001 & 0.9008 & 0.9012 \\
\hline R-sqd between & 0.1702 & 0.3289 & 0.3384 \\
\hline R-sqd overall & 0.8125 & 0.8312 & 0.8327 \\
\hline
\end{tabular}

Robust standard errors in parentheses. ${ }^{\star \star \star} p<0.01,{ }^{\star \star} p<0.05, p \mathrm{p}<0.1$. Leicester and Devon are dropped as outliers.

significant estimated parameter of around -1 . The interaction of free school meals with policy stringency is little changed. The implication is that social housing explains some, but not all, of the relationship observed in the previous subsection between poverty and social distancing.

To conclude, our evidence tentatively suggests that the relationship between poverty and poor social distancing may partly reflect poor housing, but that other factors are at play as well, such as poorer people's need for income, as noted by Brown and Ravallion (2020), and they are visible in the weakened response of WORK logins to policy stringency in poorer areas, as seen in Table 2. 


\subsection{Robustness Tests of the Modelling}

Having determined above that all four of our chosen variables show broadly consistent behavioural trends, in this subsection, we focus mainly on the robustness of modelling RESIDENTIAL logins, particularly the issues of possible endogeneity and of making the relationship with free school meals less linear.

In Table 7 we carry out some checks on alternative specifications. We start by considering the potential endogeneity of the right hand side variables in Eq. (2). Since there are lags of 2-3 weeks in the response of recorded disease cases to social distancing, ${ }^{18}$ we are less concerned with endogeneity of weekly cases, and more concerned about policy stringency, which could be seen as responding to cases.

Column (1) in Table 7 modifies the regression (1) in Table 2 by replacing the Oxford stringency variable with two dummies, for the lockdown (starting 23rd March) and pre-lockdown (starting one week earlier). This is supported by the argument that the UK, which responded later than most of its neighbours, underwent a dramatic rethink in the middle of March, shifting from a mild policy of recommended social distancing to a fairly strong lockdown in the space of a few days. Comparison with Table 2 column (1) indicates that this rather simpler representation of stringency does not make a great deal of difference to the estimated equation, but somewhat increases the proportion of the variance of RESIDENTIAL logins attributed to weekly cases. In column (2) we extend this line by instrumenting stringency with a combination of lockdown and prelockdown dummies, and the series for French policy stringency shown in Figure 2. This instrumentation produces a regression almost identical to Table 2 Column (1), indicating that the instruments are strong: however, a Sargan-Hansen test questions the statistical validity (they are correlated with English weekly cases, even if not directly caused by them). In Column (3), we modify column (1) by adding a series for national weekly cases for England: the regression suggests that endogenous social distancing is responding partly to national, and partly to local cases, although the combined effect is not greatly changed. In Column (4), we modify Column (1) of Table 2 by introducing an interaction term for weekly cases and stringency. This is strongly significant, while the term for weekly cases per capita becomes insignificant (since the two are highly correlated). One possibility is that this implies that endogenous and mandated social distancing are complementary (or that official support made endogenous social distancing decisions more viable): however, alternatively, it may simply be that, as in Chudik, Pesaran, and Rebucci (2020), there was a delay in endogenous social distancing, until the public became more aware of the problem.

18 This is confirmed empirically, results available from authors, but also makes sense given a 12 week incubation period and a further lag until diagnosis. 


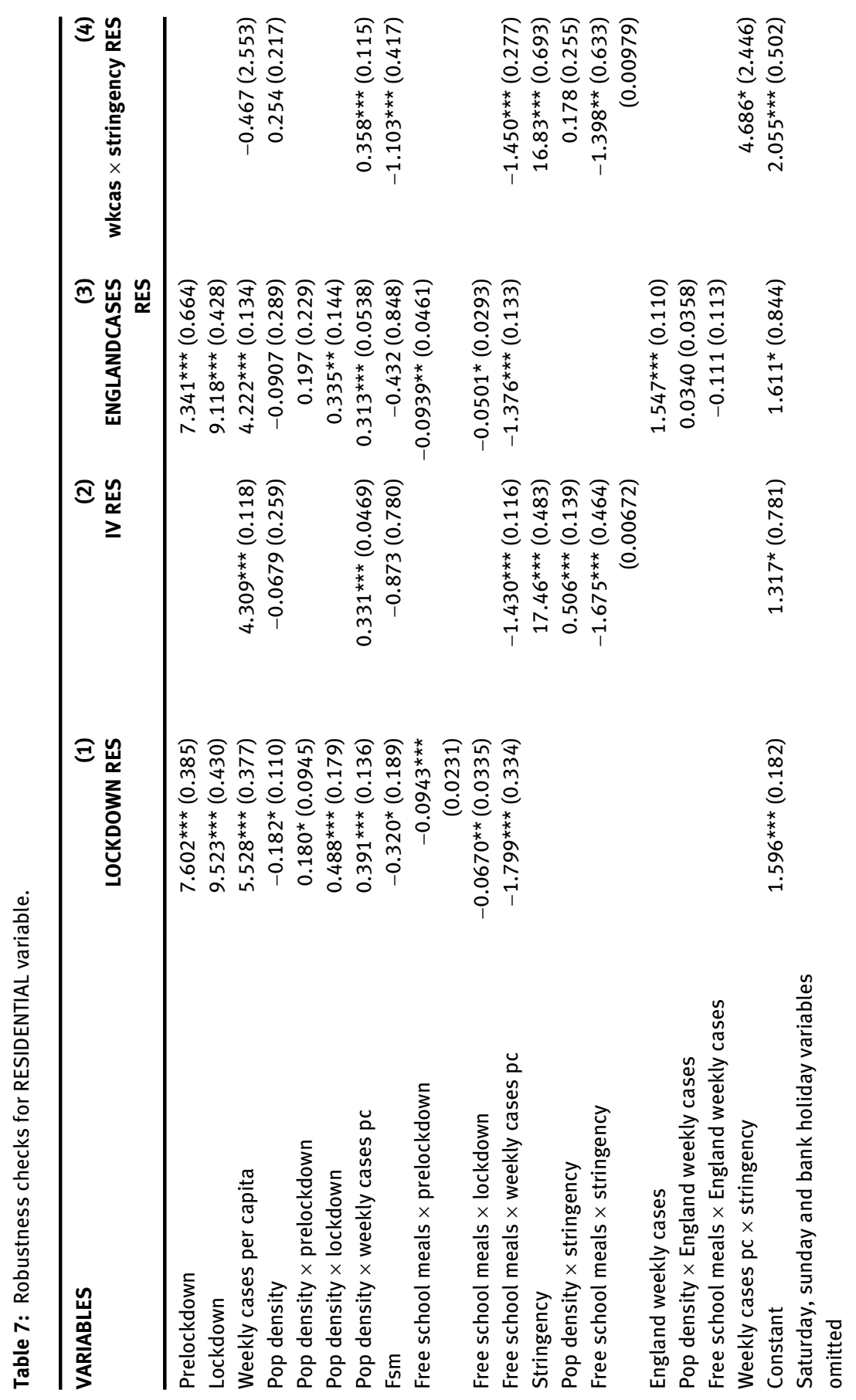




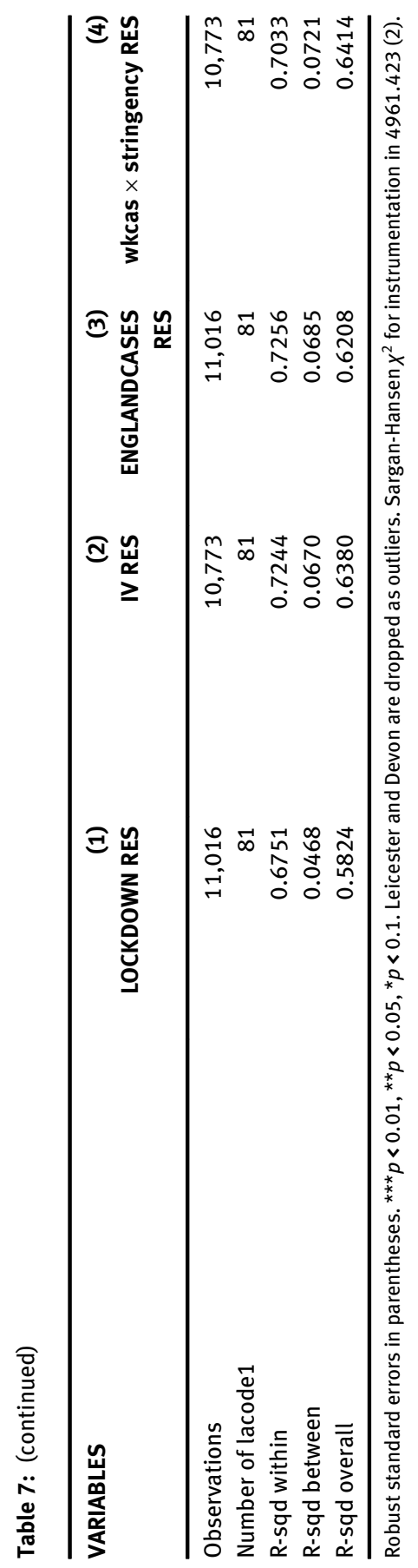


Table 8 examines the response of the RESIDENTIAL social distancing variable, by splitting UTLAs into seven groups according to free school meal uptake, from $1=$ lowest (least poverty) to $7=$ highest. This confirms the hints in the previous section that the relationship between free school meals uptake and social distancing is not strictly linear.

In summary of our empirical work, we find that social distancing responds both to policy stringency and to weekly cases, but that, in both cases, the response is significantly less where a higher share of the population receives free school meals. In the next section, we develop a stylized model to connect these empirical regularities.

\section{Social Distancing: Individual and Aggregate}

The key empirical facts presented in the preceding section are as follows. First, the poor socially distance less than the rich. Second, the poor respond less to increases in policy stringency. In this section, we employ a simple model to underpin these empirical regularities.

We consider a population in a continuum of unit interval, [0, 1]. Individual $i$ has an endowment $\omega_{i}$ and chooses his or her social distancing, $x_{i}$, with the following payoff:

$$
y_{i}=\omega_{i}-c_{i}\left(x_{i}\right)-\ell_{i}-t_{i},
$$

where $c_{i}\left(x_{i}\right)$ is $i$ 's private cost function for social distancing. We assume that this cost function is quadratic, $a_{i} x_{i}^{2} / 2$, with $a_{i}>0$, and $t_{i}$ is a lump sum tax. The loss $\ell_{i}$ arising from the chance of infection is specified as

$$
\ell_{i}=\max \left[0,\left(B-x_{i}\right) I_{i}(X)\right] .
$$

The index $I_{i}$ has an individual fixed positive component, $I_{i 0}$, and a common component that is decreasing in the aggregate social distance $X$, thus reflecting the nature of a communicable disease as a common property 'bad':

$$
I_{i}(X)=I_{i 0}-\lambda \int_{0}^{1} x_{j} d j \equiv I_{i 0}-\lambda X, \lambda>0 .
$$

The term $B-x_{i}$ reflects $i$ 's ability to reduce $I_{i}$ by choosing a personal level of social distancing closer to the environmental parameter $B$, whose value in the period under examination is fixed. A lower value of $B$ means a better environment. This parameter is common to all individuals and is determined by numerous socioeconomic factors, including population density. The environment would improve dramatically with mass vaccination using efficacious vaccines. 


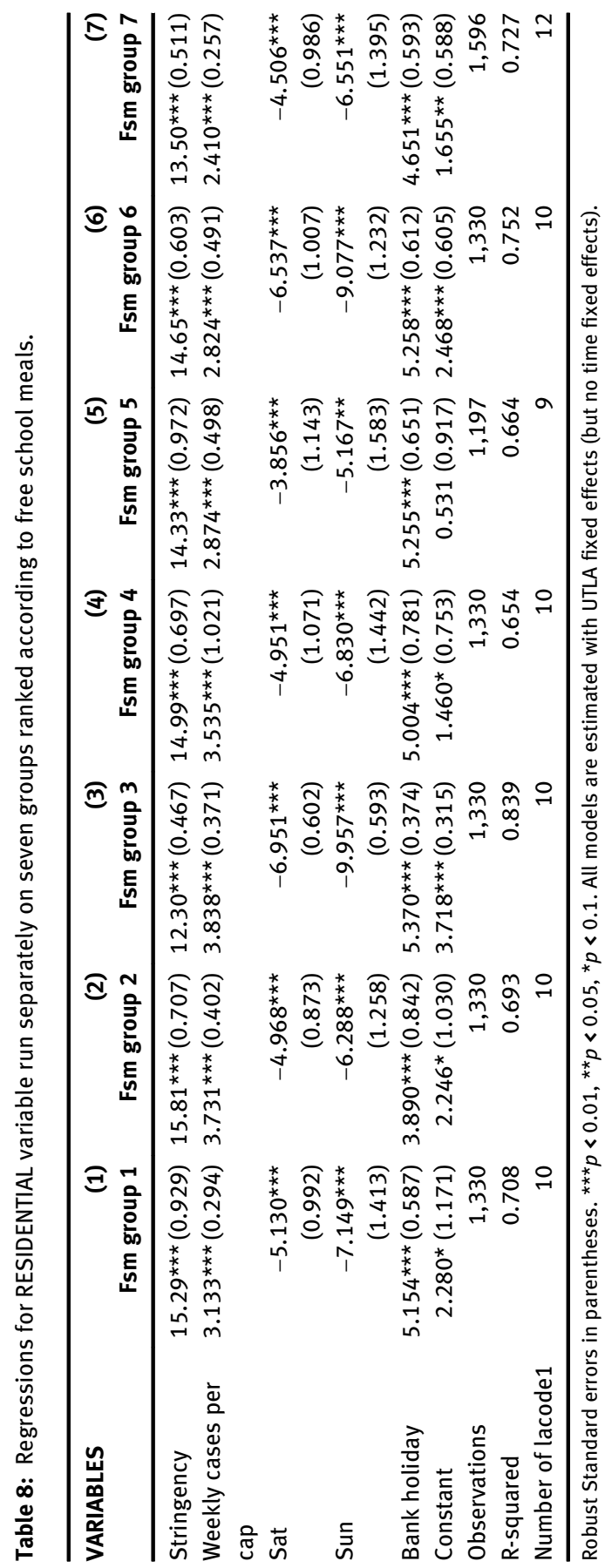


To shed light on our empirics, we consider a two-class society of poor and rich, whose members are indexed such that $P=\{i \in[0, n]\}$ and $R=\{i \in(n, 1]\}$. Given that the poor live in crowded conditions, social distancing is inherently more costly for them than the rich: $a_{p}>a_{r}$. We also assume that $I_{r 0}$ at least as large as $I_{p 0} .{ }^{19}$

Each individual takes $B, I_{i 0}$ and $\lambda$ as given when choosing $x_{i}$. It is likely that these parametric values vary across communities, which could give rise to a spectrum of geographical social distancing profiles. A local rise in infections, which could result, in part, from random influences, would increase $I_{i 0}$ in that . (As physicians and staff learn how to treat this new disease more effectively, $I_{i 0}$ could also fall, even within a few months). Two key questions arise: how does social distancing behaviour respond to such variations, and is predicted behaviour consistent with the data? ${ }^{20}$

\subsection{The Policy Problem}

The public policy tools available to improve on outcomes in the above setting are broadly of two kinds. First, the government can impose binding restrictions on individuals' choices, with penalties for violations. Secondly, the authority can invest to reduce $B$, and thus the losses $\left\{\ell_{i}\right\}$ for any given pattern $\left\{x_{i}\right\}$.

The aggregate payoff (social welfare) is

$$
W=\int_{0}^{1} y_{j} d j=\int_{0}^{1}\left[\omega_{j}-c_{j}\left(x_{j}\right)-\ell_{j}\right] d j-C(B),
$$

where $C(B)$ is the cost of the measures taken, if any, to reduce $B$. Although $W$ exhibits no aversion to inequality, the tax profile $\left\{t_{j}\right\}$ can be chosen so that taxes do not change the ranking of net endowments, $\omega_{j}-t_{j}$.

The policy problem is to maximise $W$, employing available instruments. Motivated by the findings in Section 3, we analyse measures of enforced distancing, treating $B$ as exogenous. ${ }^{21}$

19 The UK government's Coronavirus Job Retention Scheme is proportional up to a cut-off; see https://www.gov.uk/guidance/claim-for-wages-through-the-coronavirus-job-retention-scheme.

Workers may be furloughed, with the government paying $80 \%$ of salary, up to a maximum of $£ 2500$ per month. Employers may or may not make up the difference. Workers on furlough retain normal rights (statutory sick pay, pensions etc.). There is a similar scheme for the self-employed. 20 The course of this rapidly evolving epidemic is not well understood. Thus, it is not unreasonable to assume that people may take a static and short-sighted perspective when deciding on social distancing, taking the aggregate rate of infections and the resulting costs as given. We do not thus model these decisions dynamically.

21 For an analysis of the benefits of a reduction in B, see Basu, Bell, and Edwards (2020). 


\subsection{A Minimum Social Distance Rule}

The government mandates a minimum social distance $x^{s}$, with a fixed penalty $\theta$ for a violation. In practice, enforcement may be incomplete, and the probability of getting caught will depend on, inter alia, how gross the violation is. We assume that the probability of paying the penalty is $p\left(x_{i} ; x^{s}\right)=\max \left(0,1-x_{i} / x^{s}\right)$ which means that an individual pays a penalty only if he maintains less than the mandated social distance. Faced with this risk when choosing $x_{i}$, individual $i$ 's expected net pay-off is

$$
y_{i}=\omega_{i}-c_{i}\left(x_{i}\right)-\ell_{i}-t_{i}-\theta \cdot\left[\max \left(0,1-x_{i} / x^{s}\right)\right] .
$$

Individuals make Nash conjectures concerning their fellow citizens' choices of $x$ when deciding on their own distancing. Suppose that $\theta$ is sufficiently modest that $x^{s}$ is always violated to some degree. This will be called the limited-compliance regime. ${ }^{22}$ Since $y_{i}$ is strictly concave in $x_{i}$, individual $i$ 's first-order condition is also sufficient:

$$
-a_{i} x_{i}+\left(I_{i 0}+\theta / x^{s}\right)-\lambda X \leq 0, x_{i} \geq 0, i \in P, R .
$$

In a symmetric equilibrium, there is the same behaviour within each group. Let $\left(x_{p}^{\star}, x_{r}^{\star}\right)>\left(x^{s}, x^{s}\right)$ solve $(9)$. Then

$$
\begin{gathered}
x_{p}^{\star}\left(x^{s}\right)=\frac{\left(I_{p 0}+\theta / x^{s}\right) a_{r}-\lambda(1-n)\left(I_{r 0}-I_{p 0}\right)}{a_{p} a_{r}+\left(a_{r} n+a_{p}(1-n)\right) \lambda}, \\
x_{r}^{\star}\left(x^{s}\right)=\frac{\left(I_{r 0}+\theta / x^{s}\right) a_{p}+\lambda n\left(I_{r 0}-I_{p 0}\right)}{a_{p} a_{r}+\left(a_{r} n+a_{p}(1-n)\right) \lambda} .
\end{gathered}
$$

The aggregate social distance is then given by

$$
X^{\star}\left(x^{s}\right)=\frac{n\left(I_{p 0}+\theta / x^{s}\right) a_{r}+(1-n)\left(I_{r 0}+\theta / x^{s}\right) a_{p}}{a_{p} a_{r}+\left(a_{r} n+a_{p}(1-n)\right) \lambda} .
$$

Given these closed-form solutions, we have the following key proposition. ${ }^{23}$

Proposition 1: If $\left(x^{s}, \theta, B, \lambda\right)$ are such that $\ell_{i}>0(i \in P, R)$, then:

(i) $x_{r}^{\star}>x_{p}^{\star}$;

(ii) $x_{p}^{\star}$ is decreasing in $a_{p}$ and $x_{r}^{\star} / x_{p}^{\star}$ is increasing in $a_{p}$;

(iii) $X^{\star}$ is decreasing in $a_{p}$ and $n$.

22 Full compliance is a special case, which arises when the penalty is prohibitive. It is analysed in Basu, Bell, and Edwards (2020); we skip it here for brevity.

23 For the details of the algebra and the proof, see Basu, Bell, and Edwards (2020). 
Under plausible restrictions on the parameters $a_{i}$ and $I_{i 0}$, the poor socially distance less than the rich, and hence deviate more strongly from the minimum distancing rule (part i). An increase in the cost parameter $a_{p}$ has not only the expected own-effect on $x_{p}^{\star}$, but also sharpens the difference between the choices of rich and poor in equilibrium (part ii). Part (iii) is a key result. As $n$ increases, individuals who distance less replace those who distance more; but in equilibrium, changes in $n$ induce individuals of both types to change their distancing behaviour. The replacement effect dominates the individual adjustment effect. This result is consistent with the empirical finding that social distancing is less in UTLAs with a high take-up of free school meals.

A second, salient empirical finding is that the effect of stringency on $X^{\star}\left(x^{s}\right)$ is weaker when $n$ is large: recall the signs of the interaction terms free school meals $\times$ stringency for RESIDENTIAL in Table 2. In view of the abrupt lock-down in March, we compare $X^{\star}\left(x^{s}\right)$ with $X^{\star}$, noting that (12) holds for all $\theta \leq \theta^{\star}$ :

$$
X^{\star}\left(x^{s}\right)-X^{\star}=\frac{\left(n a_{r}+(1-n) a_{p}\right)\left(\theta / x^{s}\right)}{a_{p} a_{r}+\lambda\left(n a_{r}+(1-n) a_{p}\right)}=\frac{\theta / x^{s}}{\lambda+a_{p} a_{r} /\left(n a_{r}+(1-n) a_{p}\right)} .
$$

Given $a_{p}>a_{r}, X^{\star}\left(x^{s}\right)-X^{\star}$ is decreasing in $n$. Although it is increasing in the ratio $\theta / x^{s}$, that effect also weakens as $n$ increases. ${ }^{24}$ To summarise:

Proposition 2. If $\ell_{i}>0(i \in P, R)$, then the effect of the introduction of the policy $\left(x^{s}, \theta\right)$ on $X^{*}\left(x^{S}\right)$ weakens with $n$, as does the effect of an increase in $\theta / x^{s}$.

\section{Policy Implications and Conclusion}

Covid social distancing behaviour is a critical determinant of the spread of this pandemic. Using the weekly panel data for England's UTLA districts, we analyse residents' social distancing behaviour covering the period March to July 2020. Our panel regressions suggest that although stringency of social distancing rules and past infections have the desirable effect on safe social distancing of the residents, its effects are weaker in districts with a higher level of poverty. We find no evidence that this effect of poverty reflects the age or ethnic composition of poorer areas, but there is some support for the idea that this reduced social distancing reflects partly poorer housing, as well as a greater reluctance of the poor to stay away from work for financial reasons.

24 Illustrative numerical simulations are provided in Basu, Bell, and Edwards (2020). 
We develop a two-class model with a Nash non-cooperative equilibrium to understand this social distancing behaviour. The model's equilibrium is in keeping with the empirical predictions. The model also has normative policy implications for improving the Covid environment by an efficacious vaccine. The benefits rise with the level of poverty and the cost of social distancing by the poor.

At this juncture, pending widespread vaccination, safe social distancing is the only available option to combat this virus. However, social distancing is especially costly for the poor. Although the poor live in cramped conditions, home still poses lower chances of infection than the workplace and the associated round trip there, usually by public transport. Since low-income households have limited options of working remotely, a subsidy to these workers can take the form of a furlough payment, with a job retention scheme in case of job losses. The UK government has already made some progress on this front by changing the Coronavirus job retention scheme from July, and by extending furlough until March 2021. This relatively selective subsidy goes some way towards addressing our salient finding that higher levels of poverty weaken the effect of stringency on the level of social distancing in the aggregate. These subsidies could thus be targeted to low-income clusters of the economy.

\section{References}

Abedi, V., O. Olulana, V. Avula, D. Chaudhary, A. Khan, S. Shahjouei, J. Li, and R. Zand. 2020. "Racial, Economic and Health Inequality and COVID-19 Infection in the United States. Technical Report." Journal of Racial and Ethnic Health Disparities. Springer Verlag, Berlin. In this issue, https://doi.org/10.1007/s40615-020-00833-4.

Alon, T., M. Kim, D. Lagakos, and M. VanVuren. 2020. How Should Policy Responses to the COVID-19 Pandemic Differ in the Developing World? NBER Working Paper, (May).

Basu, P., C. Bell, and T. Edwards. 2020. "Covid Social Distancing and the Poor: An Analysis of the Evidence for England." CEPR COVID Economics 45: 77-110.

Bonaccorsi, G., F. Pierri, M. Cinelli, A. Flori, A. Galeazzi, F. Porcelli, A. L. Schmidt, C. M. Valensise, A. Scala, W. Quattrociocchi, and F. Pammolli. 2020. "Economic and Social Consequences of Human Mobility Restrictions under COVID-19." In Proceedings of the National Academy of Sciences of the United States of America, Vol. 117, 15530-5. Washington DC: Proceedings of the National Academy of Sciences. In this issue.

Brotherhood, L., T. Cavalcanti, D. Da Mata, and C. Santos. 2020. Slums and Pandemics. CEPR Discussion Paper No. DP15131.

Brown, C. S., and M. Ravallion. 2020. Inequality and the Coronavirus: Socioeconomic Covariates of Behavioral Responses and Viral Outcomes across U.S. Counties. NBER Working Papers, (27549).

Chan, J. 2020. The Geography of Social Distancing in Canada: Evidence from Facebook. Canadian Public Policy, Vol 46, Issue S1, July 2020, pp. S19-S28. University of Toronto Press. 
Chudik, A., M. H. Pesaran, and A. Rebucci. 2020. Voluntary and Mandatory Social Distancing. NBER Working Paper Series, 27039.

Dergiades, T., C. Milas, and T. Panagiotidis. 2020. "Effectiveness of Government Policies in Response to the COVID-19 Outbreak." SSRN Electronic Journal 1-25, https://doi.org/10. 2139/ssrn.3602004. https://papers.ssrn.com/sol3/papers.cfm?abstract_id=3602004.

Eichenbaum, M., S. Rebelo, and M. Trabandt. 2020. The Macroeconomics of Testing and Quarantining, 26882. Cambridge, MA: National Bureau of Economic Research.

Farboodi, M., G. Jarosch, and R. Shimer. 2020. "Internal and External Effects of Social Distancing in a Pandemic Internal and External Effects of Social Distancing in a Pandemic." CEPR COVID Economics 9: 25-61.

Getachew, Y. 2020. Optimal Social Distancing in SIR Based Macroeconomic Models. UNU Merit Working Paper Series, 0305(2020).

Glover, A., J. Heathcote, D. Krueger, and J.-V. Rios-Rull. 2020. "Health versus Wealth: On the Distributional Effects of Controlling a Pandemic." CEPR COVID Economics 6: 22-64.

Malaney, P., A. Sielman, and J. Sachs. 2004. "The Malaria Gap." American Journal of Tropical Medicine and Hygiene 71 (Suppl. 2): 141-6.

Mukherji, N., and N. Mukherji. 2020. The Social and Economic Factors Underlying the Impact of COVID-19 Cases and Deaths in U.S. Counties. Technical Report. Washington D.C.: Pan American Health Organization.

Palomino, J. C., J. G. Rodriguez, and R. Sebastian. 2020. "Wage Inequality and Poverty Effects of Lockdown and Social Distancing in Europe." CEPR COVID Economics 25: 186-229.

Papageorge, N., N. Zahn, M. Belot, E. van den Broek-Altenburg, S. Choi, J. Jamison, and E. Tripodi. 2020. Socio-Demographic Factors Associated with Self-Protecting Behavior during the COVID-19 Pandemic. IZA Discussion Paper, (13333).

Russel, S. 2004. "The Economic Burden of Illness for Households in Developing Countries: A Review of Studies Focusing on Malaria, Tuberculosis, and Human Immunodeficiency Virus/ Acquired Immunodeficiency Syndrome." American Journal of Tropical Medicine and Hygiene 71 (Suppl. 2): 147-55.

Toxvaerd, F. 2020. “Equilibrium Social Distancing.” CEPR COVID Economics 15: 110-34. 